
\title{
$\angle S$ Research Suare \\ Effect of Deep Mixing Grid Spacing On The Settlement of Liquefied Soil, Using Numerical Approach
}

Fereshteh Rahmani ( $\nabla$ r.fereshteh2012@gmail.com )

University of Science and Culture

Seyed Mahdi Hosseini

University of Science and Culture

\section{Research Article}

Keywords: liquefaction, soil improvement, soil-cement columns, grid-form deep mixing wall, numerical modeling

Posted Date: January 3rd, 2022

DOI: https://doi.org/10.21203/rs.3.rs-631850/v1

License: (c) This work is licensed under a Creative Commons Attribution 4.0 International License.

Read Full License 


\section{Abstract}

Liquefaction occurs in a loose and saturated sand layer, induces quite large damages to infrastructures, the importance of liquefaction mitigation has been emphasized to minimize earthquake disasters for many years. Many kinds of ground improvement techniques based on various improvement principles have been developed for liquefaction mitigation. Among them, deep mixing method with grid pattern was developed for liquefaction mitigation in the 1990s, where the grid of stabilized column walls functions to restrict the generation of excess pore pressure by confining the soil particle movement during earthquake. In this study, a parametric study of the grid-form deep mixing wall is performed using numerical modeling with GID+OpenSees interface V2.6.0. The finite element method with a three-dimensional analysis model can be used to estimate the foundation settlement over liquefiable soil layer. The validity of the developed model was evaluated by comparing the results obtained from the model with the results of numerical studies and the experimental centrifuge test to investigate the effect of deep mixing grid wall on the settlement and generation of excess pore pressure ratio of liquefiable soil. Based on the analysis, the settlement for improved soil was $69 \%$ smaller than the settlement for unimproved soil. The results also indicated that the grid wall space, relative density, and stiffness ratio between soil-cement columns and enclosed soil plays an important role in the occurrence of liquefaction and volumetric strains.

\section{Introduction}

During earthquakes shaking, may cause a loss of strength or stiffness results in the settlement of buildings, landslides, failures, or other hazards. Soil liquefaction occurred during many earthquakes in recent years (e.g., Northridge and Kobe earthquakes) and cause severe damages. Soil liquefaction is most often observed in saturated loose granular materials such as sands because the interaction of soil and pore fluid under earthquake or other dynamic loadings may lead to the build-up of pore pressure, which results in soil loses shearing resistance and fails like a viscous liquid. In order to reduce the settlement of foundations and improve the bearing capacity of the soil, various soil improvement techniques have been used including stone columns (SC), preloading and prefabricated vertical drains (PVD), dewatering, and insitu mixing of admixtures such as lime and cement called deep soil mixing method (Adalier and Elgamal, 2004). Among these methods, DSM method has attracted a great deal of attention worldwide.

One way to prevent liquefaction is to use a grid-form deep mixing wall. The grid-mixing wall in liquefiable soil is formed by wrapping improved soil-cement columns that may overlap each other. The DSM grid can improve the performance of a site by reducing the shear strain, increasing resistance against lateral deformations, and providing a barrier against high excess pore pressure in the enclosed soil by the grid (Rayamajhi et al 2012). This method helps to achieve significant improvement of mechanical and physical properties of the soil, which involves the auger mixing of soils extending to large depths with binders such as cement, lime, or other types. 
Case history studies showed the performance of the grid wall soil improvement by using a Deep Cement Mixing method. The cement-treated soil walls were produced with overlapping columns and the area ratio was approximately $20 \%$ for a 14 -story building that was observed to affect its settlement in the Hyogoken Nanbu earthquake 1995 (Suzuki et al., 1996a; Tokimatsu et al., 1996). DSM grids and in-ground shear walls performed well during the 1995 Kobe earthquake, the results indicate that ground improvement by cement-mixing could mitigate the damage to the pile foundation and the structures, although the liquefaction of the soil layer had caused severe damage to the quay walls (Hamada and Wakamatsu 1997). The effectiveness of DSM grids for remediating against liquefaction has been studied using physical models with the centrifuge tests and shaking tables (e.g., Suzuki et al. 1991, Kitazume and Takahashi 2010, Farouk and Shahien 2013, Tsukuni et al 2013, Kazuhiro and Masayuki 2017), and Numerical analysis of DSM grids include equivalent two-dimensional (2D) and three-dimensional (3D) models with (FE) analysis (Naimikava et al 2007) the results show that the area ratio is the most parameter controlling treatment effectiveness, followed by elastic modulus of improved soil.

Other studies illustrate the effect of DSM grids on the dynamic shear stress and strain distributions in the loose sand of a unit cell in OpenseesPL (Elgamal et al 2009, Neguen et al 2012) and the effect of pore water pressure on controlling settlement of numerical simulation for mitigation liquefaction by using gridform deep mixing walls on a liquefiable soil layer below a non-liquefiable layer with an elastoplastic constitutive model using the SYS-Cam clay model for the soil (Kazuhiro and Masayuki 2017).

There are a limited number of researches on the beneficial effect of a non-liquefiable soil layer created by ground improvement beneath ground surface for the reduction of liquefaction induced foundation settlements and the prevention of bearing capacity failure. Particularly, soil improvement by DSM is relatively limited for liquefaction mitigation in liquefiable soil layer, and the influence of some important design factors remains unclear. From literature review, previous researches had some limitations. First, lack of sufficient investigation on the effects of DSM method in grid pattern on the relationship between the foundation settlement and grid wall space for liquefaction mitigation of a thick liquefiable soil layer over a non-liquefiable soil layer and their seismic behavior. Second, lack of sufficient investigation on the effects of parameters like DSM columns and soil characteristics for a DSM grid.

In this study, a parametric study of DSM grid pattern on controlling liquefaction, decreasing settlement, and excess pore water pressure ratio of liquefied soil is investigated using three-dimensional (3D), finite element (FE) analysis in GID + Opensees interface V2.6.0. The validity of the developed model was evaluated by comparing the results obtained from the model with the results of numerical studies and the experimental centrifuge test (Tsukuni et al 2013). using this well-developed model, extensive parametric analyses were conducted for the liquefiable soil layer improved by deep mixing grid in terms of grid wall space, the diameter of DSM wall, relative density of liquefiable soil, and stiffness ratio between soilcement column and enclosed soil to examine the effects of grid walls on the foundation settlement and excess pore water pressure ratio depending upon the depth of the liquefiable layer which develops during pseudo-static or dynamic loading. 
These analyses were performed using a graphical user interface developed specifically for DSM grid systems, and which provides the ability nonlinear, coupled soil models in future works. In the following sections we describe the configuration of the soil-cement grid wall that were analyzed, the FE model, analysis platform, and also results from from dynamic loading cases.

\section{Characteristics Of Centrifuge Experiment}

The use of centrifuges in geotechnics is well documented (Madabhushi, 2014). Dynamic centrifuge experiment was chosen because they can realistically recreate the response of liquefiable layers, with the correct stress and strain levels as in the modeled prototype.

A dynamic centrifuge test was performed by (Tsukuni et al 2013) at university of Tokyo to investigate the effectiveness of soil-cement grid walls on the foundation settlement over liquefiable soil layer. This study focuses on the relationship between the space of DSM grid and the settlement. The dimension of the model was $48 \star 14 \star 31.8 \mathrm{~m}$ on the prototype scale. In the experiment, the liquefied layer was made using Toyoura sand and Urayasu sand (a standard sand in japan). Urayasu sand was taken from erupted soil from Urayasu during the 2011 Tohoku earthquake. The D value for controlling the density of Urayasu sand is defined as the ratio for the maximum dry density $\left(\rho_{\mathrm{dmax}}=1.451 \mathrm{t} / \mathrm{m}^{3}\right)$. Toyoura sand was controlled using the relative density.

The D value of Urayasu sand (90\%) and Dr of Toyoura sand (50\%) correspond roughly to an $\mathrm{N}$ value of 5 . Similarly, the D value of Urayasu sand (95\%) and Dr of Toyoura sand (70\%) correspond roughly to an $\mathrm{N}$ value of 10. Modeling of the liquefied stratum was based on the $90 \%$ D value of Urayasu sand (Toyoura sand: $\mathrm{Dr}=50 \%$ ) at GL $0 \mathrm{~m}$ to $\mathrm{GL}-8 \mathrm{~m}$, and the $95 \%$ D value of Urayasu sand (Toyoura sand: $\mathrm{Dr}=70 \%$ ) at $\mathrm{GL}-8 \mathrm{~m}$ to $\mathrm{GL}-12 \mathrm{~m}$.

This experiment consists of two liquefiable layer thickness $\left(H_{\perp}\right)=8$ and $4 m$ (in prototype scale) on the base layer is non-liquefiable gravel with shear wave velocity $V s \geq 400 \mathrm{~m} / \mathrm{s}$, which was placed in a laminar box via dry pluviation. Figure 1 shows the grain size distribution of Toyoura sand and Urayasu sand, the fine content of Urayasu sand which used in the centrifuge experiment was adjusted to $25 \%$. The groundwater level was adopted as $1.0 \mathrm{~m}$ below the ground surface, the model was saturated with Silicone oil (50CS) as void liquid below a depth of $1 \mathrm{~m}$. The laminar box is constructed of rectangular aluminum rings on top of each other with roller bearings in between. Figure 2 presents cross-section view of gridform ground improvement model with 1 structure per grid square in a grid spacing of $16 \mathrm{~m} * 13 \mathrm{~m}$ (in fullsize scale conversion), and the instrumentation used for the centrifuge experiment to measure the horizontal and vertical response of acceleration and excess pore water pressure. Table 1 shows the plane and cross-sectional views for 2 simulated cases of dynamic centrifuge model test. A $60 \mathrm{G}$ field was used for testing.

Case 1 represents grid-form ground improvement with 2 structures per grid square in a grid spacing of $32 \mathrm{~m} * 13 \mathrm{~m}$ with the area replacement ratio $A_{r}=12 \%$. Case 2 is simultaneous modeling of grid-form ground 
improvement with 1 structure per grid square in a grid spacing of $16 \mathrm{~m}^{\star} 13 \mathrm{~m}$ with $A_{r}=15 \%$ (represent by full-size scale conversion). The dimensions of residential structures were $8.0 \mathrm{~m}$ (direction of earthquake motion) and $11.0 \mathrm{~m}$ (orthogonal to the direction of the earthquake). The spacing between the grid walls was defined as the distance from the center of the improved walls. The spacing between the residential structure models was $2.0 \mathrm{~m}$, and the center of the improved wall was $1.0 \mathrm{~m}$ from the residential structure model.

The grid-wall soil improvement model was made of acrylic, with a width of $0.9 \mathrm{~m}$ (Young's modulus $\mathrm{E}=$ $\left.1.47 \times 10^{3} \mathrm{MPa}\right)$ and a standard design strength $\mathrm{f}_{\mathrm{c}}=1.5\left(\mathrm{~N} / \mathrm{mm}^{2}\right)$. The model was spun at a centrifuge acceleration of $60 \mathrm{~g}$ and excited horizontally of a magnitude 9.0 Tohoku earthquake in 2011 with peak ground acceleration (PGA) of about 157gal at the base of the shaking box reproduced in Fig. 3 (the time history chart of seismic waves), the principal shock lasted for more than 2 minutes. This created a condition under which liquefaction easily occurred in a reclaimed land consisting of loose sand.

TABLE 1.Experimental cases (Tsukuni et al 2013)

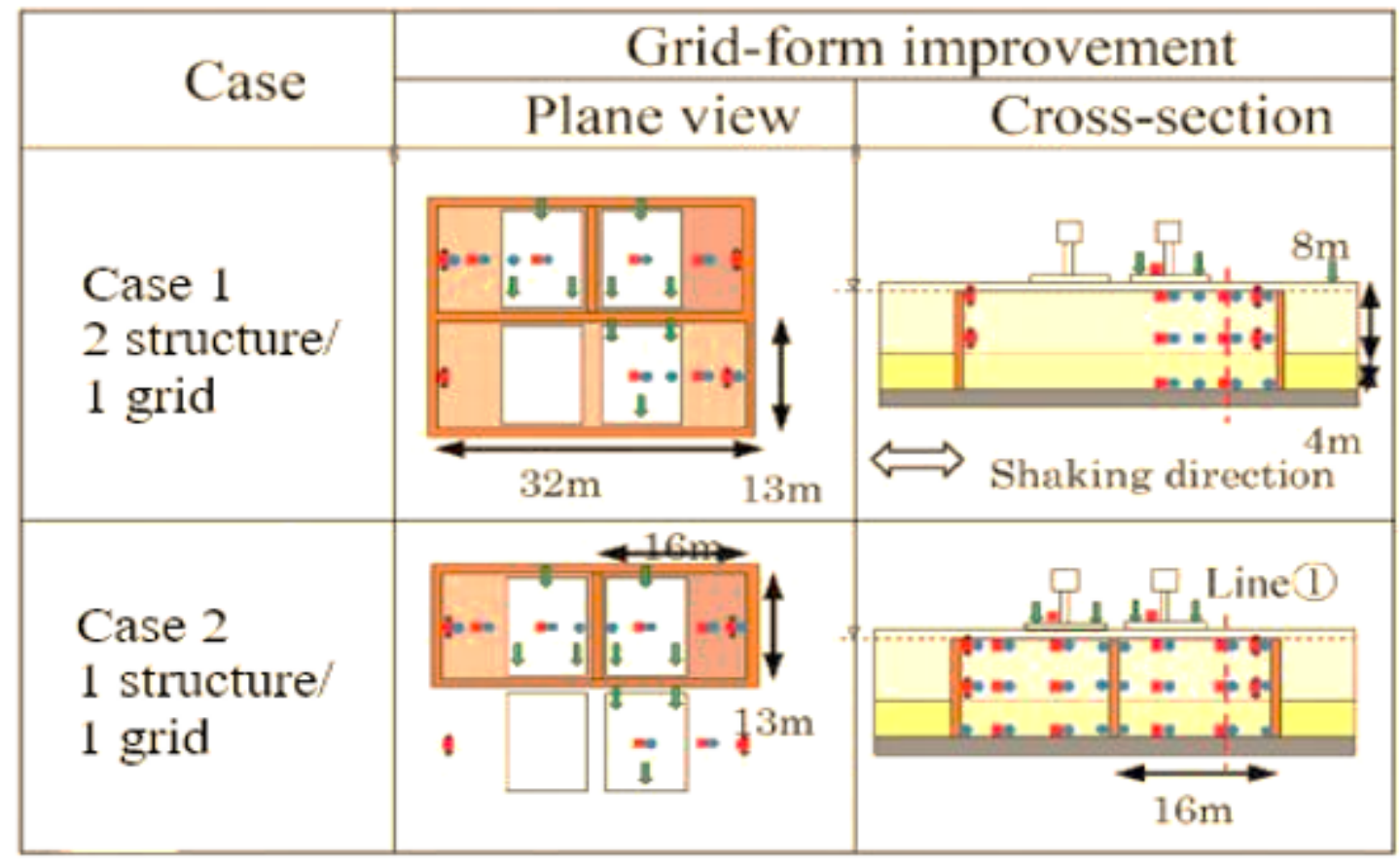

\section{Numerical Modeling}

GID + OpenSees Interface is a user-friendly graphical interface for the open-source finite element software OpenSees (Mazzoni et al 2006), suitable for modeling and analysis of structural as well as geotechnical problems (It is an add-on (problem type) for GID and is available as an open-source, under the GNU General Public License. It consists of a collection of utilities that allows the user to interact using a Graphical User Interface (Papanikolaou et al 2017).

According to Fig. 4, it features the Pre and Post graphical capabilities provided by GID in addition to the powerful text-only tool for numerical simulation of structural and geotechnical systems, OpenSees solver, 


\section{Numerical Modeling Assumption}

At first, we present the result of numerical simulation for the effect of grid-wall soil improvement in mitigation liquefaction, conducted using GID + OpenSees finite element framework, and then comparisons with the results obtained from the centrifuge experiment. For the numerical simulation, the 3D models with nonlinear solid-fluid fully coupled effective stress dynamic finite-element (FE) analyses were performed in the GID + OpenSees platform. Analyses were performed for both improved and unimproved soil profiles (i.e., omitting the DSM walls) so that the responses could be compared. The goal was to evaluate the settlement over liquefiable soil layer with and without soil improvement on the liquefiable ground as observed in the centrifuge.

The soil model employed in this study PDMY01(The pressure-dependent, multiple-yield-surface) by (Yang et al 2000), is based on the multi yield surface plasticity model initially introduced by Iwan (1967) and Mroz (1967) and later implemented for soils by Prevost (1985), as an elastic-plastic material for simulating the essential response characteristics of pressure-sensitive soil materials under general loading conditions for Urayasu sand in the centrifuge.

This model is defined by means parameters and a set of user-defined backbone curve parameters, (Table 2). The maximum shear modulus is determined from shear wave velocity measurement, the parameters controlling liquefaction triggering are mainly contract and the phase transformation angle (PtAng); the parameters controlling dilation behavior are mainly dilation rate constant 1 and dilation rate constant 2, and the parameters controlling post-liquefaction shear strain are mainly liquefaction parameter 1 , liquefaction parameter 2 , and liquefaction parameter 3 .

The soil elements were modeled using 20 - 8 node brick u-p elements (Lu et al. 2004; Yang et al. 2008). using the trilinear isoparametric formulation which can be simulated only in 3D models and each node has 3 translational degrees of freedom. The saturated soil was modeled as a two-phase material based on the Biot theory (Biot 1962) for porous media, in which displacement of the soil skeleton, $u$, and the pore water pressure, $p$, are the primary unknowns $u-p$ formulation (Shiomi \& Zienkiewicz1984). A total number of 8067 nodes and 7148 elements for unimproved soil and 9320 nodes, 8106 elements for improved soil were used in the presented numerical simulations. The soil-cement columns and soil around the columns were modeled using the contact interface model. The material of the interface is elastic perfectly plastic, which consists of an elastic range and a perfectly plastic that works only in compression with force-deformation or moment-rotation formulation for the corresponding field. It is used with a Zero Length Section element.

The bottom boundary condition was a viscous boundary which used the Lysmer-Kuhlemeyer (1969) and the side boundary condition used an energy transfer boundary. While a mass system model was used to model structures in the dynamic centrifuge model test, solid elements were used to model structures in the simulation because the natural frequency of structures had only a small effect on the experimental 
results. The foundation elements were connected to the soil elements by a contact interface zone with Zero Length element and elastic-perfectly plastic (works only in compression) material. The proper mesh is based on a concept of an adequate number of elements fit within the wavelength of a shear wave. This shear wave is calculated as the ratio of the lowest shear wave velocity and the highest frequency desired to be resolved.

Table 2

PDMY01 model parameter for sand in GID + OpenSees analyses

\begin{tabular}{|llll|}
\hline Soil Type & $\begin{array}{l}\text { Urayasu sand } \\
\left(\mathbf{N}_{\text {SPT }}=5\right)\end{array}$ & $\begin{array}{l}\text { Urayasu sand } \\
\left(\mathbf{N}_{\text {SPT }}=10\right)\end{array}$ & $\begin{array}{l}\text { Gravel and } \\
\text { Dense Sand }\end{array}$ \\
\hline Saturated soil mass density (ton/m3) & 1.822 & 1.865 & 2.00 \\
\hline Reference Shear Modulus (MPa) & 3.7 & 44.6 & 117.696 \\
\hline Reference Bulk Modulus (MPa) & 9.62 & 115.96 & 220.002 \\
\hline $\begin{array}{l}\text { Reference Mean Effective Confining } \\
\text { Pressure (kPa) }\end{array}$ & $80 \mathrm{kPa}$ & $80 \mathrm{kPa}$ & $80 \mathrm{kPa}$ \\
\hline Friction Angle & 34.20 & 34.80 & 38 \\
\hline Phase Transformation Angle & 29 & 29 & 27 \\
\hline Peak Shear Strain (at pr'=80kPa) & 0.1 & 0.1 & 0.1 \\
\hline Pressure Dependent Coefficient & 0.5 & 0.5 & 0.5 \\
\hline Contraction Rate Constant & 0.21 & 0.20 & 0.03 \\
\hline Dilation Rate Constant1 & 0 & 0.02 & 0.8 \\
\hline Dilation Rate Constant1 & 0 & 0 & 5 \\
\hline Liquefaction Parameter 1 $(\mathrm{kPa})$ & 10 & 10 & 0 \\
\hline Liquefaction Parameter 2 $(\mathrm{kPa})$ & 0.02 & 0.02 & 0 \\
\hline Liquefaction Parameter 3 $(\mathrm{kPa})$ & 1 & 1 & 0 \\
\hline Permeability (cm/s) & $1.67 \mathrm{E}-05$ & $9.05 \mathrm{E}-06$ & $2.00 \mathrm{E}-04$ \\
\hline Poisson's ratio & 0.33 & 0.33 & 0.33 \\
\hline
\end{tabular}

\section{Results And Comparison}

\subsection{Verification of numerical and experimental results}

Finite element Pre- and post-processing software GiD + OpenSees V2.6.0 was used as an interface for OpenSees analyses. Effect of the soil-column grid in liquefiable sand was numerically simulated and analyzed in terms of footing settlement time-history and excess pore water pressures ratio for 
unimproved soil and improved soil with $16 \mathrm{~m} * 13 \mathrm{~m}$ DSM grid (one structure exist in a grid) and $32 \mathrm{~m} * 13 \mathrm{~m}$ DSM grid (two structures exist in a grid), on line 1 according to the Fig. 5

Fig. 6 present comparisons between experimental and numerical results. The numerical results are from the GID+OpenSees analyses using the as-built soil properties and the input motion of Tohoku earthquake with peak ground acceleration of $157 \mathrm{~g}$ were recorded at the base of the container during the experiment. Fig. 6 compares the recorded and computed time history of the footing settlement during 200s. The computed settlement for unimproved soil is approximately $68 \mathrm{~mm}$ as against $83.5 \mathrm{~mm}$ observed in the experiment, for improved soil with $16 \mathrm{~m} \star 13 \mathrm{~m}$ DSM grid is $21 \mathrm{~mm}$ as against $17 \mathrm{~mm}$ in the experiment, and for $32 \mathrm{~m} \star 13 \mathrm{~m}$ DSM grid is $45 \mathrm{~mm}$ against $37 \mathrm{~mm}$ in the experiment. The improved soil settlement was $69 \%$ smaller than the settlement for unimproved soil. Soil improvement with DSM grid has reduced the rate of settlement as well as the maximum amount of settlement. The analytical results corresponded well with the experimental results. From the results, we realized that soil improvement in form of DSM grid was carried out to mitigate damages of liquefaction, the footing settlement was controlled, and the effect of the soil improvement was apparent.

Figure 7 through 9 compares experimental and analytical results for the time history of excess pore water pressure ratio $\left(r_{u}\right)$ in unimproved and improved soil with $13 \mathrm{~m} * 16 \mathrm{~m}$ and $32 \mathrm{~m} * 13 \mathrm{~m} \mathrm{DSM}$ grid. The measurement points of $r_{u}$ are situated on ground level 2,7 , and $12 \mathrm{~m}$ from the ground surface on line 1 according to Fig. 5.

For excess pore water pressure ratio $\left(r_{\mathrm{u}}\right.$, where $r_{\mathrm{u}}=\Delta \mathrm{u} / \sigma^{\prime} ; \Delta \mathrm{u}=$ excess pore pressure and $\sigma^{\prime}=$ initial effective confining pressure) value of 0.9 or greater, liquefaction is expected. From the results, the amount of $r_{u}$ at GL $12 \mathrm{~m}$ from the ground surface in experimental and analytical results for unimproved soil was 1 and 0.96 , for soil improvement with $32 \mathrm{~m} * 13 \mathrm{~m}$ grid was 0.95 and 0.88 , and for $16 \mathrm{~m} * 13 \mathrm{~m}$ grid was 0.95 and 0.83 so liquefaction occurs in all cases. Comparison of unimproved soil case and the improved cases showed that $r_{u}$ decreased after soil improvement with DSM grid. Experimental results also showed the rise of excess pore water pressure in the liquefiable soil without soil improvement was slightly greater than the liquefiable soil with DSM grid, and excess pore water pressure rose until liquefaction occurred in deep areas, while in shallow areas the results showed a smaller rise of excess pore water pressure (Tsukuni et al 2013). Analytical results showed the same. According to the results, the analytical excess pore pressure ratio was roughly equivalent in the centrifuge measurements at all locations.

Fig. 10 presents contour maps of maximum excess pore water pressure ratio in the experimental and analytical results. With the comparison of experimental and analytical results, we realized that using $32 \mathrm{~m} * 13 \mathrm{~m}$ and $16 \mathrm{~m} * 13 \mathrm{~m}$ grid squares showed a similar pattern rise of excess pore water pressure generation in shallow areas. By decreasing the grid area, it tends to a small rise, and this tendency was more pronounced in the case of a smaller $16 \mathrm{~m} * 13 \mathrm{~m}$ grid. The cause of difference between experimental and analytical results can be explained as a limitation in dividing nodes in GID+OpenSees and maximum shear strain near the wall which leads to a pattern of a greater rise in excess pore water pressure. 
Fig. 11 and 12 compare experimental and analytical results for horizontal response acceleration at ground level $2 \mathrm{~m}$ with the input motion for unimproved soil and improved soil with a $16 \mathrm{~m}^{\star} 13 \mathrm{~m}$ DSM grid. Hence, the acceleration response of the soil surface becomes one of the identifying factors in evaluating the performance of the soil improvement techniques. The analytical acceleration generally compares well with the experimental ones. In the case of unimproved soil, the results appear to capture the reductions in ground shaking at shallow depths in Urayasu sand due to liquefaction because of pore water generation in the underlying layers.

\section{Parametric study}

Parametric analyses in this study were performed to investigate the effect of parameters of soil-cement columns characteristics included dynamic analysis results for excess pore water pressure ratio $\left(r_{u}\right)$ and the settlement over liquefiable soil improved by DSM grid walls.

\section{Effect of DSM grid wall space}

Three different DSM grid wall spaces with the same condition of the centrifuge test for improved soil with DSM grid were analyzed to investigate the relation between grid wall space and the settlement. We modeled $32 \mathrm{~m} \star 13 \mathrm{~m}, 16 \mathrm{~m} \star 13 \mathrm{~m}$, and $10 \mathrm{~m} \star 13 \mathrm{~m}$ grids. The spacing between the center of the DSM walls was $32 \mathrm{~m}, 16$, and $10 \mathrm{~m}$. According to Fig. 13 , the results present the maximum settlement and excess pore water pressure ratio tend to decrease with smaller grid wall space because of more stiffness and shear stress on enclosed soil, through decreasing the distance between DSM walls, the extent of $r_{u}$ also decreased. In the case of $32 \mathrm{~m} * 13 \mathrm{~m}$, and $16 \mathrm{~m} * 13 \mathrm{~m}$ grids liquefaction occurred but in the smallest grid size $(10 \mathrm{~m} \star 13 \mathrm{~m})$ no liquefaction occurred by decreasing the shear strains of the soil so it prevented liquefaction. The cases of $32 \mathrm{~m} \star 13 \mathrm{~m}$ and $16 \mathrm{~m} \star 13 \mathrm{~m}$ grid have the same rate of excess pore water pressure generation at depths of 2,7 , and $12 \mathrm{~m}$ from the ground surface.

Effect of the diameter of DSM wall

Fig. 14 presents the effect of different diameters of $16 \mathrm{~m} \star 13 \mathrm{~m}$ DSM walls on the settlement and excess pore water pressure ratio over liquefiable soil. The dynamic analysis was conducted for improved soil using the DSM walls with diameters of $0.9,0.8$, and $0.7 \mathrm{~m}$. Accordingly, changes of $\mathrm{r}_{\mathrm{u}}$ were evaluated at depths of 2, 7, and $12 \mathrm{~m}$ on line 1 in Fig. 5. The results indicate that at the depth of $12 \mathrm{~m}$ from the ground surface, the improved soil experienced partial liquefaction, and with an increase of the DSM wall diameter, the risk of liquefaction decreases. However, this decrease is not significant. In the case of using DSM walls with the smallest diameter, the radius of influence decreased. This means that by decreasing the diameter of soil-cement columns, a lower area around the liquefiable soil will not safe from the risk of liquefaction and the settlement tends to increase, but it can't prevent liquefaction so the changes in the diameter of grid walls had little effect on mitigation liquefaction. Generally, the effectiveness of grid walls is not improved by increasing the diameter of grid walls.

Effect of the relative density of the liquefiable soil layer 
Fig. 15 presents the effect of different relative densities of the liquefiable layer. The model in the experimental test consists of two liquefiable soil layers with $\mathrm{N}_{\mathrm{SPT}}=5$ and $10, \mathrm{D}_{\mathrm{r}}=50$ and $70 \%$ which aren't acceptable so we considered these relative densities with the properties of Nevada sand, we analyzed again and compared the results. The two other models had similar loading histories, but different relative densities for the liquefiable layers. In the numerical models, relative density was considered 40 and $60 \%$ for the liquefiable layers according to the parameters of Nevada sand. Comparing these results, increasing relative density of the liquefiable layers to 40 and $60 \%$ showed down the rate of excess pore water pressure generation at all depths and positive effects on the settlement of liquefiable soil layer. This effect was greater for the higher relative density as expected, the influence of soil relative density on its resistance to pore pressure generation depends on the state of stress and ground motion intensity.

Effect of stiffness ratio $\left(G_{r}\right)$

The analytical analysis was performed with different ratios of stiffness for the effectiveness of soilcement columns on liquefaction remediation. For this purpose, numerical models were carried out with stiffness ratios $G_{r}=20.8,25$, and 38.75. $G_{r}$ shear-modulus ratio $\left(G_{\text {soil-cement }} / G_{\text {soil }}\right) ; G_{\text {soil-cement }}$ is shear modulus of the soil-cement column; and $G_{\text {soil }}$ is shear modulus of soil. The analysis results were evaluated based on the effect of soil-cement columns under varying stiffness ratios on the distribution of the settlement and excess pore water pressure ratio in the liquefiable soil layers and shown at various depths of 2, 7, and $12 \mathrm{~m}$ within liquefiable soil layers extending from a depth of $1 \mathrm{~m}$ to $12 \mathrm{~m}$ in Fig. 16. It was seen that soil-cement columns attracted a great portion of the shear stresses compared to the surrounding soil as they are stiffer than the liquefiable soil layer. The settlement and damages due to liquefaction decreased with increasing the stiffness of soil-cement columns and affected the occurrence of liquefaction.

\section{Conclusion}

Mitigation techniques have become essential in vulnerable areas which are prone to severe damage caused by earthquake induced liquefaction. In this study, a series of parametric studies are carried out to investigate the effectiveness of DSM grid walls in liquefaction mitigation. The finite element analysis for unimproved soil and improved soil with soil-cement columns was performed with the PDMY01 model in GID + OpenSees V2.6.0. The results of the numerical analysis were evaluated in terms of settlement timehistory and excess pore water pressure ratio at different depths of liquefiable soil. A numerical analysis is initially verified with centrifuge studies. The numerical analysis is in good agreement with the experimental results. The bearing capacity of enclosed soil increased and provided resistance against lateral deformations or vertical settlements by reducing the shear strains and the rate of excess pore water pressure generation in a DSM grid. The results of this study showed that soil improvement with DSM grids could not always prevent the liquefaction but it controlled damages such as tilting and ununiform settlement during liquefaction. From the analysis, in $32 m \star 13 m$ and $16 m \star 13 m$ grid walls liquefaction occurred but the settlement over liquefiable soil layer has decreased. We propose an affordable and suitable solution to use the $32 \mathrm{~m} * 13 \mathrm{~m}$ DSM grid with $A_{r}=12 \%$ and 72 Ton used cement 
(two structures in a grid) for soil improvement instead of the $16 \mathrm{~m} * 13 \mathrm{~m}$ DSM grid with $A_{\mathrm{r}}=15 \%$ and 92 Tone used cement (one structure in a grid) because of the same function during liquefaction and the rate of excess pore water pressure generation. In this way, cement consumption $20 \%$ reduced. Parametric study showed that grid area and relative density of the liquefiable soil layer have the main effect on liquefaction remediation. At the end, it should be noted that the results obtained from present study can be used in practical engineering applications as well as in investigating the effect of DSM grid walls located over liquefiable soil.

\section{Declarations}

\section{Authors Contribution}

S.M Hosseini made substantial contributions to conception, revised it critically for important intellectual content, and read and approved final approval of the final manuscript; F Rahmani participated in the collection, design, and interpretation of the data, performed numerical analysis, wrote the paper, and participated in the revisions of it.

\section{Data availability}

All data generated from the experimental results during this study are included in this published article [DOI: 10.3208/jgs.9.761].

\section{Conflict of interest}

The authors declare that they have no potential conflict of interest with the study in this paper.

\section{References}

1. Adalier K, Elgamal A (2004) Mitigation of liquefaction and associated ground deformations by stone columns. Eng Geol 72:275-291. https://doi.org/10.1016/j.enggeo.2003.11.001

2. A.Farouk MM, Shahien (2013) Ground improvement using soil-cement columns: an experimental investigation. Alexandria Eng J 52(4):733-740. https://doi.org/10.1016/j.aej.2013.08.009

3. Biot MA (1962) The mechanics of deformation and acoustic propagation in porous media. J Appl Phys 33(4):1482-1498. https://doi.org/10.1063/1.1728759

4. Elgamal A, Lu J, Forcellini D (2009) Mitigation of liquefaction-induced lateral deformation in a sloping stratum: three-dimensional numerical simulation. J Geotech Geoenviron Eng 135(11):1672e1682. https://doi.org/10.1061/(ASCE)GT.1943-5606.0000137

5. Hamada M, Wakamatsu K (1997) "Liquefaction-Induced Ground Displacement Triggered by Quaywall Movement, Soils and Foundations, Volume 38, pp. 85-95. https://doi.org/10.3208/sandf.38.Special_85 
6. Kaneda K, Masayuki Imai. Preventing liquefaction by using grid-form deep mixing walls on a liquefiable soil layer below a non-liquefiable layer. Proceedings of the 19th International Conference on Soil Mechanics and Geotechnical Engineering. 2017

7. Kitazume M, Takahashi H (2010) "Centrifuge model tests on effect of deep mixing wall spacing on liquefaction mitigation". In: 7th Intl. Conf. on Urban Earthquake Engineering (7CUEE) \& 5th Intl. Conf. on Earthquake Engineering (5ICEE). Tokyo Institute of Technology, Tokyo, pp 473-478

8. Lysmer J, Kuhlemeyer RL (1969) Finite Dynamic Model for Infinite Media. Journal of Engineering Mechanics Division 95:859-878

9. Madabhushi SPG (2014) Centrifuge Modelling for Civil Engineers. Taylor \& Francis, London

10. Mazzoni, S., McKenna, F., Scott, M. H., and Fenves, G. L. (2009). Open system for earthquake engineering simulation user manual, University of California, Berkeley Calif. $<$ http=//opensees. berkeley.edu>.

11. Namikawa T, Koseki J, Suzuki Y (2007) Finite element analysis of lattice-shaped ground improvement by cement mixing for liquefaction mitigation. Soils Found 47(3):559-576. https://doi.org/10.3208/sandf.47.559

12. Nguyen TV, Rayamajhi D, Boulanger RW, Ashford SA, Lu J, Elgamal A, Shao L, (2012), "Effects of DSM grids on shear stress distribution in liquefiable soil", Proceedings GeoCongress 2012, State of the Art and Practice in Geotechnical Engineering, ASCE GSP 255, Oakland, CA, PP. 1948-1957. https://doi.org/10.1061/9780784412121.200

13. Rayamajhi D et al (2012). "Effect of discrete columns on shear stress distribution in liquefiable soil" Proc., Geo-Congress 2012: State of the Art and Practice in Geotechnical Engineering, ASCE, Reston VA, 1908-1917. https://doi.org/10.1061/9780784412121.196

14. Suzuki K, Babasaki R, Suzuki Y (1991), “Centrifuge tests on liquefaction proof foundation," Proceedings of Centrifuge 91, Balkema, 409-415

15. Suzuki Y, Satio S, Onimaru S, Kimura T, Uchida A, Okumura R (1996a) Grid-shaped stabilized ground improve by deep cement mixing method against liquefaction for a building foundation, Tsuchi-toKiso. JGS 44(3):46-48 (in Japanese)

16. Tokimatsu K, Mizuno H, Kakurai M (1996) Building damage associated with geotechnical problems, Special Issues of Soils Foundations, 219-234. https://doi.org/10.3208/sandf.36.Special_219

17. Tsukuni S, Uchida A, Honda T, Konishi K (2013) Dynamic centrifuge model test focused on the settlement of the residence improved with grid-form deep mixing walls. Japanese Geotechnical Journal 9(4):761-771. https://doi.org/10.3208/jgs.9.761 (in Japanese).

18. Papanikolaou VK, Kartalis Kaounis T, Protopapadakis EK, Papadopoulos T, "A New Graphical User Interface for OpenSEES," 2017

19. Yang Z (2000) "Numerical modeling of earthquake site response including dilation and liquefaction." PhD dissertation, Dept. of Civil Engineering and Engineering Mechanics, Columbia University, New York 
20. Zienkiewicz OC, Shiomi T (1984) Dynamic behaviour of saturated porous media; The generalized Biot formulation and its numerical solution. Int J Numer Anal Meth Geomech 8:71-96. https://doi.org/10.1002/nag.1610080106

\section{Figures}

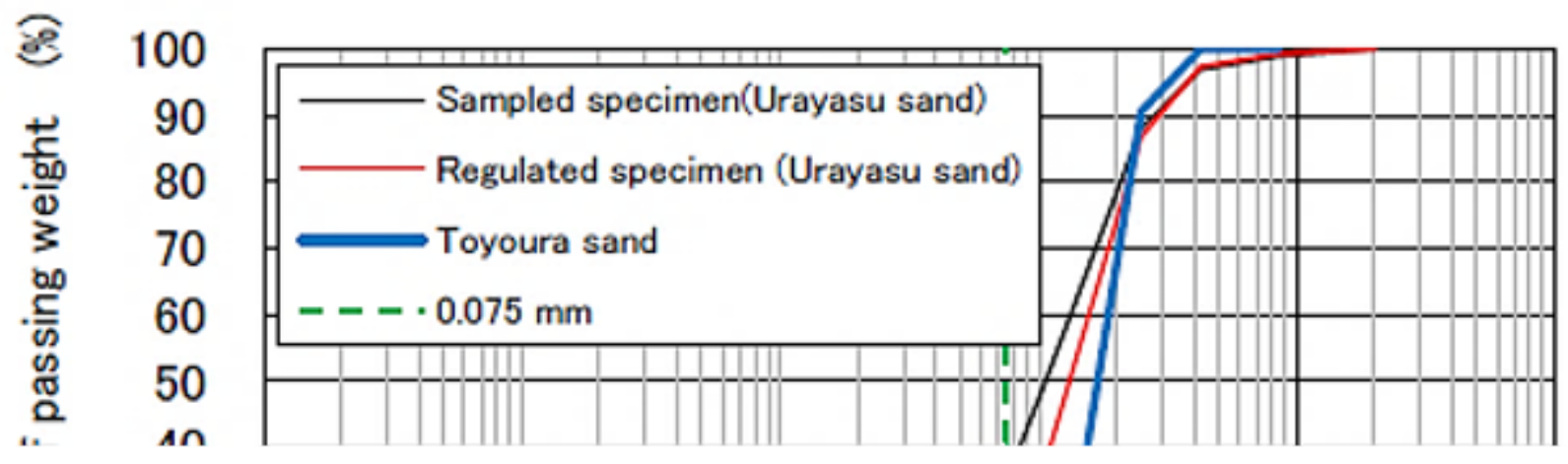

\section{Figure 1}

Grain size distribution for standard sands in Japan (Tsukuni et al 2013) 


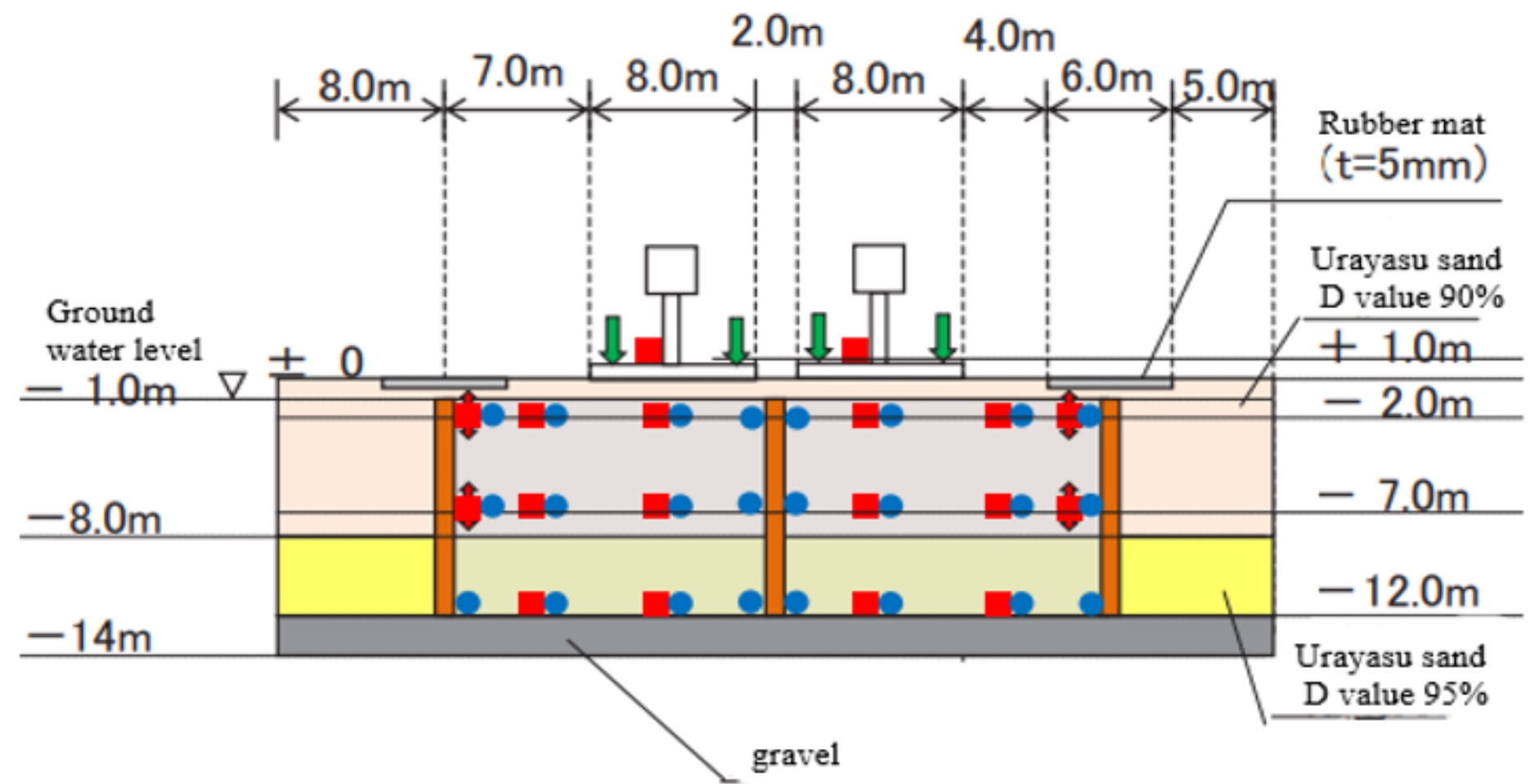

Figure 2

Cross-section view of the centrifuge experiment (Tsukuni et al 2013)

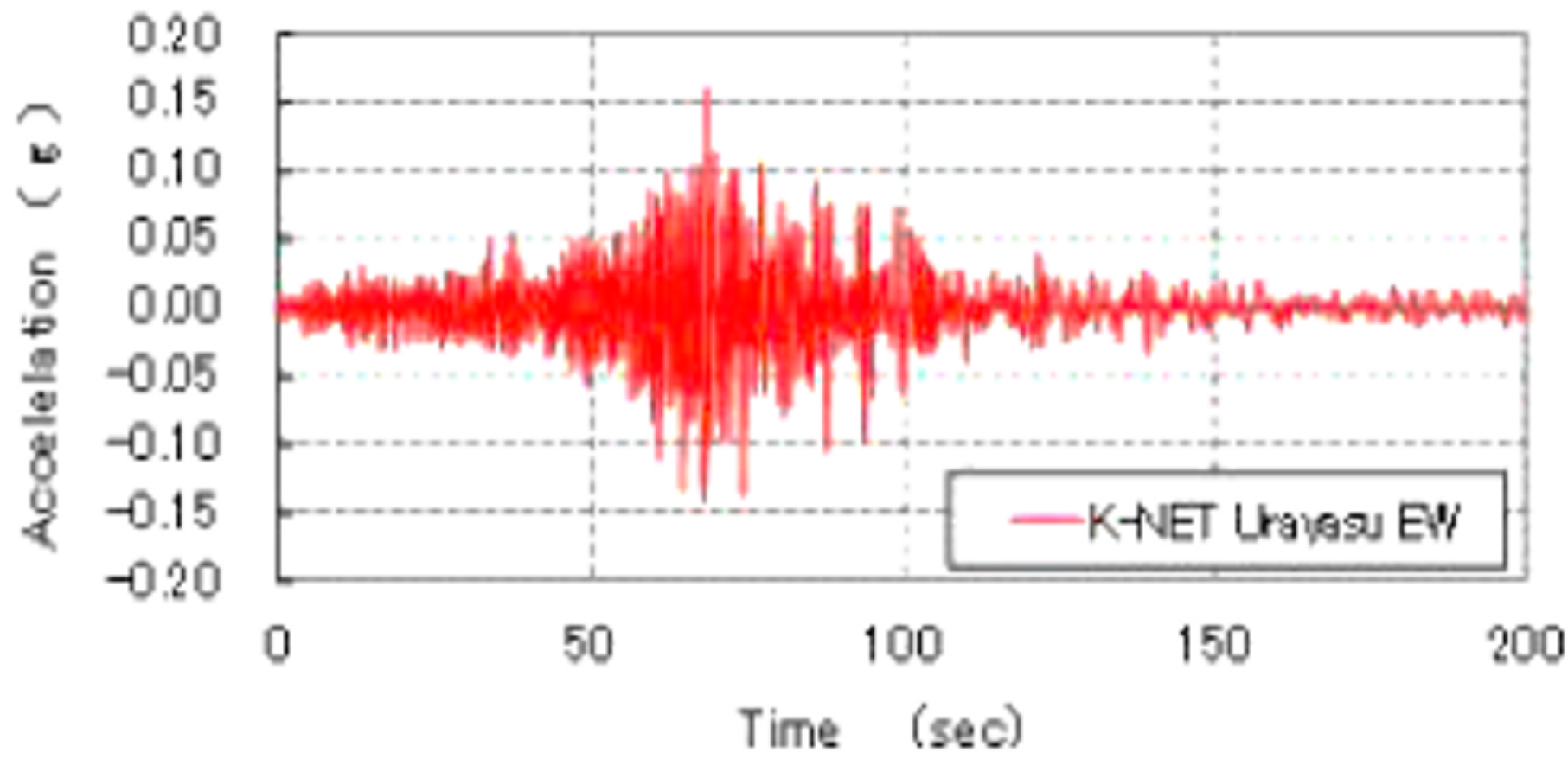

Figure 3 
Horizontal input motion at the bottom (Tsukui et al 2013)

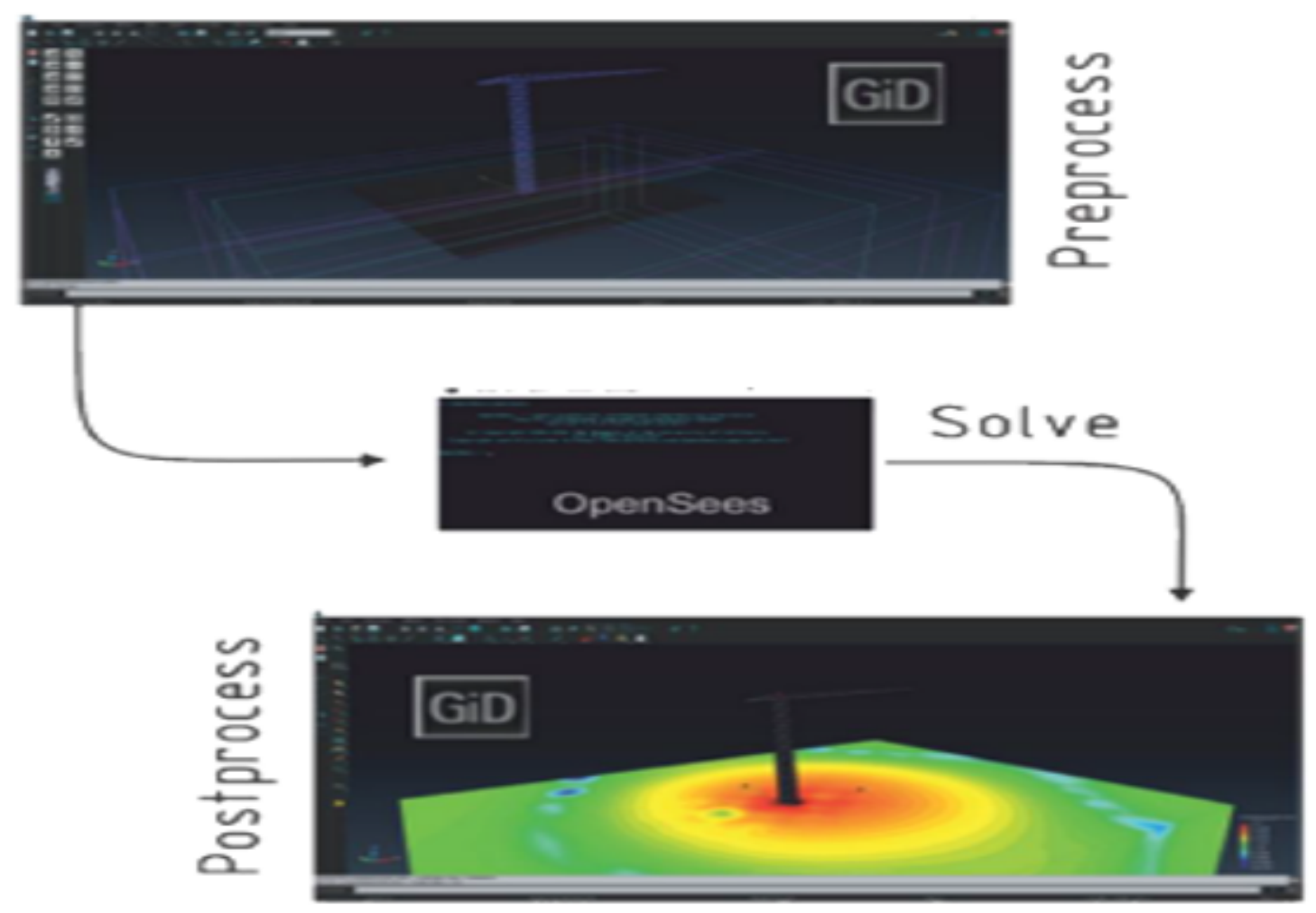

Figure 4

GID+OpenSees Interface Structure

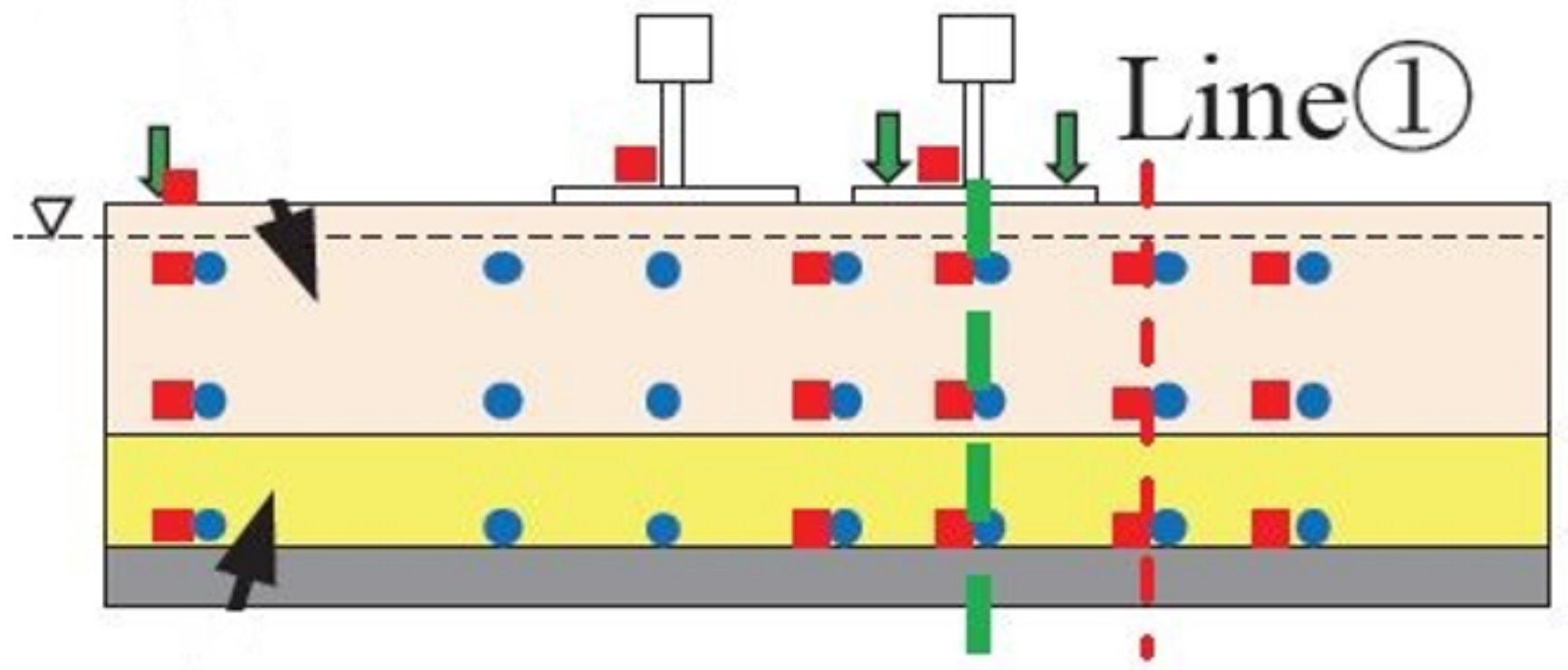

Figure 5

Line 1 for computing results (Tsukuni et al 2013) 


\section{Figure 6}

Numerical and experimental comparison of time-history settlement for unimproved soil and improved soil with grid $32 \mathrm{~m} * 13 \mathrm{~m}$ and grid $16 \mathrm{~m} * 13 \mathrm{~m}$
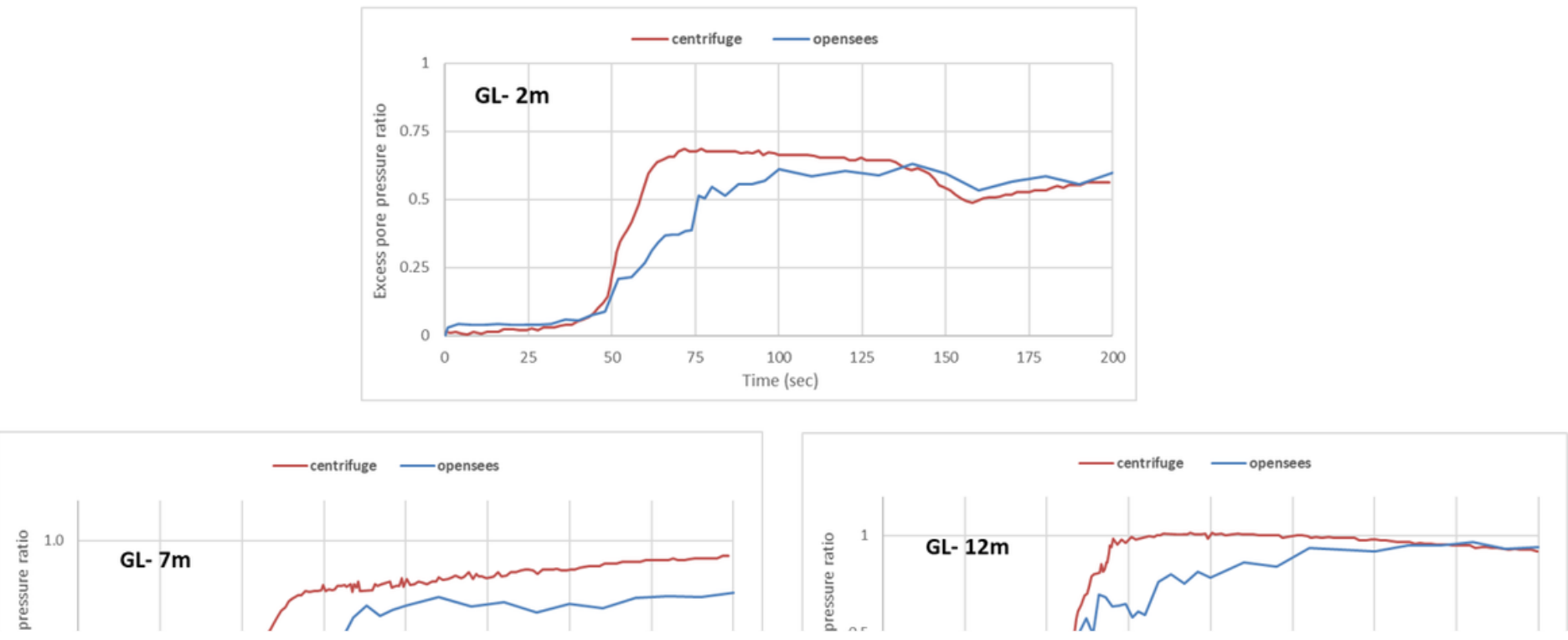

\section{Figure 7}

Numerical and experimental comparison for time-history of excess pore pressure ratio at GL 2, 7, and $12 \mathrm{~m}$ without soil improvement 


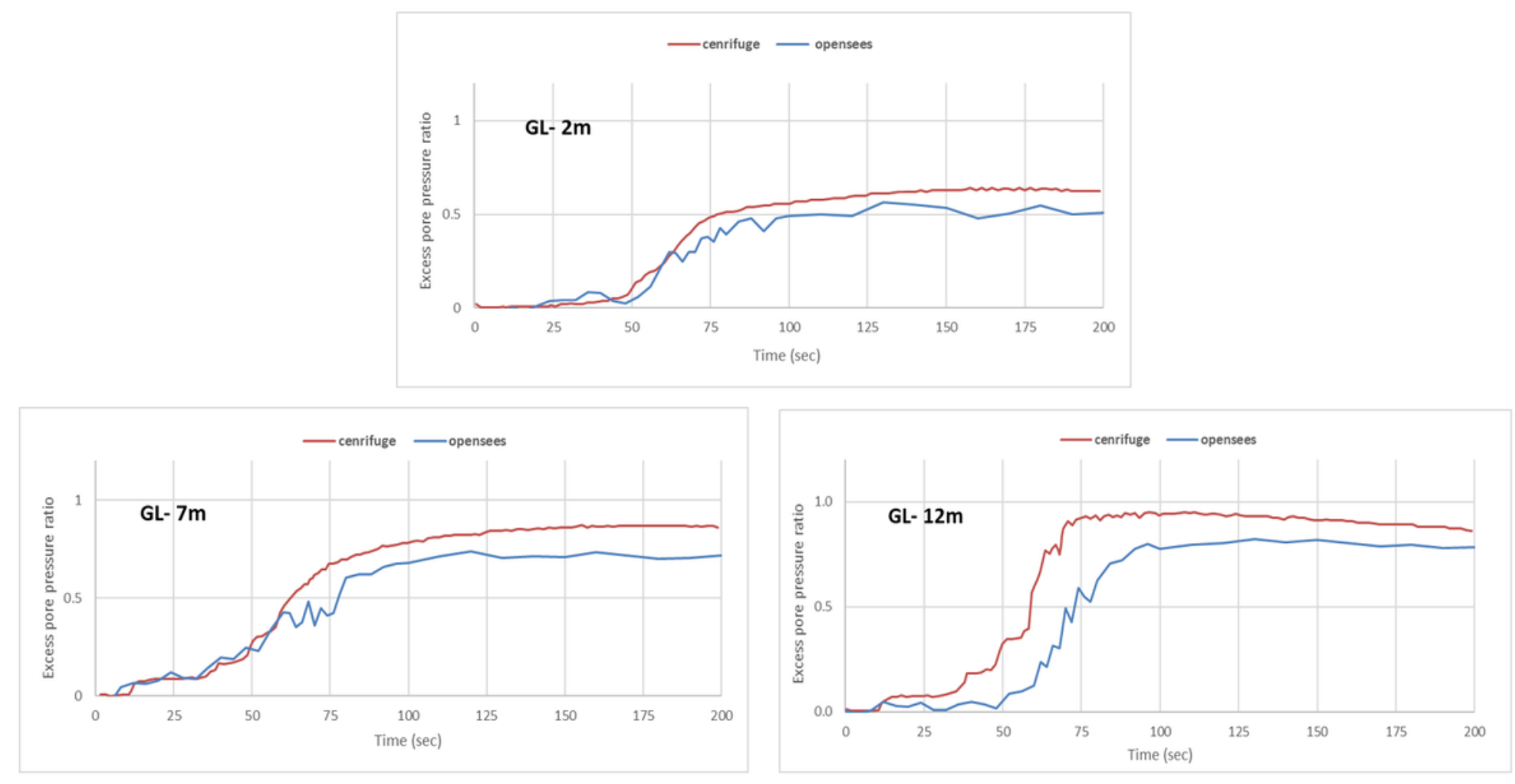

\section{Figure 8}

Numerical and experimental comparison for time-history of excess pore pressure ratio at GL 2, 7, and $12 \mathrm{~m}$ with $16 \mathrm{~m} * 13 \mathrm{~m}$ grid of soil improvement

Figure 9

Numerical and experimental comparison for time-history of excess pore pressure ratio at GL 2, 7, and $12 m$ with $32 m * 13 m$ grid of soil improvement

\section{Figure 10}

Contour maps of maximum excess pore water pressure ratio (a): experimental results; (b): analytical result

\section{Figure 11}

Time history-based comparison of horizontal response acceleration in unimproved soil 
Figure 12

Time history-based comparison of horizontal response acceleration in improved soil with $16 \mathrm{~m} \star 13 \mathrm{~m}$ DSM grid

Figure 13

Comparison of different grid wall space (a): Max settlement, (b): excess pore water pressure ratio

Figure 14

Comparison of different diameter ( $d=0.7,0.8$ and 0.9 ) of DSM walls (a): Max settlement, (b): excess pore water pressure ratio

\section{Figure 15}

Comparison of different relative densities $\left(D_{r}=40,50,60\right.$ and 70) for liquefiable layers (a): Max settlement, (b): excess pore water pressure ratio)

\section{Figure 16}

comparison of different stiffness ratios $\left(G_{r}=38.75,25\right.$ and 20.8) (Left: Max settlement, Right: excess pore water pressure ratio) 